\title{
El poder del coleccionismo de arte: Alvar Carrillo Gil
}

\author{
Renato González Mello
}

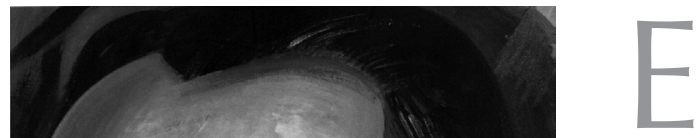

n El poder del coleccionismo: Alvar Carrillo Gil, Ana Garduño hace la

- historia social de una colección de arte y, junto a ello, un retrato bastante complejo de un coleccionista, cuya biografía puede ubicarse sólidamente en el México de los años cuarenta y cincuenta del siglo pasado, cuando fue funcionario público y empresario. Alvar Carrillo Gil no fue (salvo, quizá, durante una breve temporada como médico rural) un activista; sí en cambio, un hombre del régimen. Sus alternativas fueron semejantes a las de otros personajes que aparecen en el libro de Garduño, como Miguel Salas Anzures, primero maestro rural cardenista, y más adelante funcionario modernista en el Instituto Nacional de Bellas Artes (INBA). Carrillo Gil contribuyó a la articulación de una identidad en torno de la modernidad de la estética mexicana y de su transformación. El arte moderno era parte del acervo retórico del régimen posrevolucionario desde los años veinte, pero Carrillo Gil le añadió la riqueza de sus reflexiones y una colección de obras de caballete y gráfica que permitieron tener una historia del arte mexicano con un acervo coherente y distinto, no opuesto a los acervos estatales.

Esa diferencia puede entenderse en la flexibilidad con la que el médico y empresario reformulaba la narrativa central de su acopio, incorporando primero a José Clemente Orozco, luego a David Alfaro Siqueiros, pero también a Rufino Tamayo, José Luis Cuevas y Gunther Gerzso. Artistas salían y entraban de su colección, articulando cada vez en forma distinta una visión histórica que nunca acabó de fijarse del todo, porque para su dueño era una extensión de sus propias dudas y cambios de perspectiva.

El personaje me parece emblemático también en la manera muy inteligente que utilizó para proponer sus intervenciones en un espacio público que, en los años cincuenta y sesenta, tenía pocas fisuras para la expresión de disidencias y alternativas. En su libro, Garduño lo examina -en ocasiones muy exigente con él, aunque siempre en un tono bastante respetuoso- como un actor social típico de su tiempo y, a la vez, completamente singular. Lo ve como un personaje un tanto ensimismado en su proyecto. No consecuenta -como prácticamente no lo ha hecho nadie- sus ambiciones como pintor; a la postre, y al compararlo con otros coleccionistas, la evaluación es bastante positiva. Garduño no analiza la pintura incluida en la colección; su problema no son los cuadros, sino las personas. Sin incurrir en la fantasía del historiador como juez, hace un esfuerzo por considerar equilibradamente la biografía del coleccionista; señala, con mucha intuición, que no todas las exhibiciones de 
arte mexicano en cuya organización participó fueron realmente curadas por él, aunque se apresura a aclarar que casi siempre realizó gestiones de alto nivel con las instituciones y con otros coleccionistas para que los proyectos pudieran finalmente llevarse a efecto. Su examen de los avatares de la relación con Siqueiros, Tamayo y Cuevas mantiene el interés, a veces, de una comedia de enredos, que en otros pasajes se convierte en drama psicológico. Por ejemplo, donde narra su bombástica ruptura con Rufino Tamayo. Lo más bonito de este capítulo es la referencia de que, tras repudiar al amigo, Carrillo Gil se tomara su tiempo para deshacerse de sus cuadros. Qué pena que lo haya hecho. Trato de imaginar cómo hubiera sido la historiografía del arte mexicano durante el último medio siglo, si la colección Carrillo Gil hubiera conservado un importante lote de obras de Tamayo.

El capítulo final, dedicado a examinar las relaciones del coleccionista con el Estado mexicano, se mantiene tenso entre el azoro por las ambiciones del coleccionista y un asombro, igualmente importante, por que sus ambiciones se vieran cumplidas con frecuencia. Aunque reconoce algunas de las críticas de Inés Amor y otros contemporáneos, terminan por parecerle parciales: lo son porque la búsqueda de notoriedad pública, indudable, no se contrapone con el interés genuino y denso por el arte mexicano. En último término, y a semejanza de la famosa galerista, Alvar Carrillo Gil aspiró a realizar funciones públicas desde la esfera privada. No concibió el ámbito de su labor como un sistema fundamentalmente opuesto al de los intereses públicos y, en particular, no pretendió distinguirse ideológicamente del nacionalismo oficial.

En este sentido, los momentos de mayor tensión del estudio parecen pasajes de alguna novela de Sergio Pitol o de Luis Spota. Garduño despoja a los personajes de sus presunciones mediante un recurso bastante sencillo: narra meticulosamente sus actos, enumera a los asistentes a las inauguraciones como si fuera cronista de sociales, se fija en el pequeño desaire y el halago trivial, interpreta los gestos menores de la burocracia, cita y refiere la correspondencia ocasional de los grandes personajes (como Octavio Paz) y concluye haciendo un retrato de costumbres que espanta un poco, no por el coleccionista y sus cuadros, sino por el medio social en el que se desarrollaron. Es el retrato de una elite política y cultural apoyada declaradamente en las instituciones del gobierno nacionalista. Sí, pero las relaciones personales se conservaban intensamente como una de las fuentes de la vida social, política y cultural. Y así, Octavio Paz, recibiendo unos collages, cuyo autor era el coleccionista, le responde con esta carta: "Lo envidio (en el peor sentido de la palabra). Le debo, le debemos todos, una gran alegría. Tenía (y tengo) gran afecto por el hombre y profunda estimación por el artista: hoy esa estimación se ha transformado en admiración".

El recado es un poco raro, y quizá lo interesante es que actualiza la incomodidad con ese tipo de gestos, acaso menores, que Paz conservó hasta el final y por artistas cuyo estatus no se disputa: la incomodidad es la misma cuando se dirige así a Manuel Felguérez o a José Luis Cuevas. Ese alarde público del "tú" (o el "usted") y el "yo" es un gesto fósil de los años cuarenta; digamos: como si de pronto hubiera cobrado vida una película de Fernando Soler. Esta especie de Manual de Carreño, ya fuera de lugar, no es exclusivo de Paz y simplemente señala los límites de un discurso que se concebía completamente impersonal, revolucionarioinstitucional, desarrollo-estabilizador y con mucha-marcha-hacia-el-mar, pero en el que también había recaditos y abrazos con palmadita.

Más importante y menos anecdótico, resultan las rupturas políticas e intelectuales que se codificaban en ese sistema. Desde luego, uno podría pensar que el sistema cultural en el que participaban ambos, Paz y Ca- rrillo Gil, no era una fiesta de buenos modales, y aquí está la significación de los personajes.

Porque Paz, más que nadie, denunció al sistema lúcidamente: lo denunció como un leviatán autoritario y cerrado. Las polémicas de Alvar Carrillo Gil son anteriores a ese ejercicio paradigmático, y se formularon en una época en que la tolerancia del Estado era mucho menor. CarriIlo Gil inicia o interviene en distintas polémicas sobre asuntos artísticos y políticos. En sus participaciones no hay un deslinde del sistema en su conjunto, pero sí un ejercicio crítico. La maraña de consideraciones personales no debe borrar el panorama: lo que Garduño señala es el desfase entre el auge del nacionalismo en las artes plásticas, en la primera mitad del siglo pasado, y, en la segunda, el de sus coleccionistas. Espléndido desfase. Más que una paradoja, es uno de los procesos importantes del siglo xx mexicano. Al mediar los años cuarenta, la violencia ha terminado y cualquier pretensión de heroísmo ha quedado atrás. Numerosos funcionarios, intelectuales y burócratas han sido, en su juventud, maestros rurales, activistas o militantes; algunos pueden recordar hechos de armas. Ya no, pero ahora se esmeran -con bastante éxito- en reciclar la memoria del pasado inmediato (el ensayo de Alfonso Reyes se publica en 1947).

Por eso llaman tanto la atención los debates, y por eso son muy valiosos: rompen el autoritarismo de las relaciones personales (de ahí que sean iracundos). Las polémicas en las que interviene Carrillo Gil no son con los enemigos del gobierno; digamos, no se pelea con un obispo, con la derecha católica o con algún tipo de disidencia comunista. Son disputas sobre la memoria común, entre hombres maduros que riñen sobre el significado de lo ocurrido tres o cuatro décadas atrás. Carrillo Gil no se enfrenta al Estado directamente si puede evitarlo -salvo cuando la policía invade su casa para arrestar a David Alfaro Siqueiros-. 
Su pretensión es corregir las políticas públicas o sumarse a ellas; no puede concebirse fuera de los márgenes de la hegemonía del Estado. La suya no es una política de las alternativas.

Comparado con otros coleccionistas de la época, como Marte R. Gómez y Dolores Olmedo, destaca por su conciencia de una historia de las artes plásticas autónoma y universal. Creo que aquí es donde está su singularidad como coleccionista y hombre público, como polemista e intelectual: Carrillo Gil se sabía parte de la historia política moderna de México, pero también concebía un relato distinto y que imponía sus pro- pias reglas. Su propia práctica de la abstracción pictórica y sus frecuentes artículos de divulgación dan cuenta de este matiz de gran importancia; ambicionaba escribir en uno y otro libros: el de historia universal y el de historia de México. Además de permitirle dialogar con los frecuentes proyectos diplomáticos del Estado, este objetivo doble le permitió formular nuevas alternativas dentro del sistema y no fuera del mismo. Todo se organiza gracias a esa mirada (del coleccionista) que me atrevo a calificar de introspectiva: una casa-bodega que funge, además, como espacio para recibir a los visitantes y aficio- nados, con un complejo sistema de jardines diseñado por Luis Barragán; un par de catálogos, muy tempranamente editados, sobre la colección de obras de Orozco; un museo cuyo modelo es el Guggenheim, como un inmenso panóptico que privilegia la visión desde el interior hacia el interior; un jardín de árboles bonsai y una práctica pictórica que se conciben como parte del mismo proyecto intelectual, de tal manera que la colección y el museo terminan por ser la exhibición de una personalidad que se divide hacia el infinito dentro de sus propios confines. 